\title{
Yeast-based Biochemical Oxygen Demand Sensors Using Gold- modified Boron-doped Diamond Electrodes
}

\author{
Tribidasari A. IvANDINI, $* * *$ HARMESA, ${ }^{* *}$ Endang SAEPUdin, $* *$ and Yasuaki EINAGA $* * * * \dagger$ \\ *Department of Chemistry, Faculty of Science and Technology, Keio University, 3-14-1 Hiyoshi, \\ Yokohama 223-8522, Japan \\ **Department of Chemistry, Faculty of Mathematics and Sciences, University of Indonesia, Kampus Baru UI, \\ Depok, Jakarta 16-424, Indonesia \\ ***JST CREST/ACCEL, 3-14-1 Hiyoshi, Yokohama 223-8522, Japan
}

\begin{abstract}
A gold nanoparticle modified boron-doped diamond electrode was developed as a transducer for biochemical oxygen demand (BOD) measurements. Rhodotorula mucilaginosa UICC Y-181 was immobilized in a sodium alginate matrix, and used as a biosensing agent. Cyclic voltammetry was applied to study the oxygen reduction reaction at the electrode, while amperometry was employed to detect oxygen, which was not consumed by the microorganisms. The optimum waiting time of 25 min was observed using 1-mm thickness of yeast film. A comparison against the system with free yeast cells shows less sensitivity of the current responses with a linear dynamic range $\left(R^{2}=0.99\right)$ of from $0.10 \mathrm{mM}$ to $0.90 \mathrm{mM}$ glucose (equivalent to $10-90 \mathrm{mg} / \mathrm{L} \mathrm{BOD}$ ) with an estimated limit of detection of $1.90 \mathrm{mg} / \mathrm{L}$ BOD. However, a better stability of the current responses could be achieved with an RSD of 3.35\%. Moreover, less influence from the presence of copper ions was observed. The results indicate that the yeast-immobilized BOD sensors is more suitable to be applied in a real condition.
\end{abstract}

Keywords Gold-modified diamond, BOD sensors, oxygen, Rhodotorula mucilaginosa UICC Y-181, alginate matrix

(Received February 26, 2015; Accepted March 30, 2015; Published July 10, 2015)

\section{Introduction}

The oxygen content is one of the important parameters, which is generally monitored to control the water quality. The oxygen content was mostly measured as dissolved oxygen, chemical oxygen demand (COD), and biochemical oxygen demand (BOD). While a strong chemical agent is applied to oxidize the organic material for COD measurements, microorganisms are used for BOD measurements. The established method for BOD measurements needs 5 days to grow microorganisms in a water sample before only measurement of the amount of the consumed oxygen by microorganisms can be performed. ${ }^{1}$ Therefore, the method is not suitable for a continuous controlling and monitoring process.

On the other hand, microbial-based BOD sensors are potential as an alternative of the conventional method. ${ }^{2-5}$ These sensors were reported to decrease the time of BOD measurements from 5 days to be around $30 \mathrm{~min}^{2-5}$ In addition to that, these sensors can provide a specific analysis with high sensitivity and inexpensive cost. Low limits of detection (LODs) were also reported..$^{3-5}$

Previously, our groups have reported the use of yeast-based BOD sensors. ${ }^{3}$ Gold-modified boron doped diamond (AuBDD) electrodes were used as the detector of oxygen, from which the measurements of oxygen consumed by yeast can be

$\dagger$ To whom correspondence should be addressed.

E-mail: einaga@chem.keio.ac.jp calculated. A better performance than Au bulk electrode was found. The proposed reason was because the gold nanoparticles (AuNPs) modifying the boron-doped diamond (BDD) can provide a hemispherical diffusion, resulting in a higher signalto-background ratio., ${ }^{3,6}$ BDD itself is known as an established electrode due to its superior property, including a wide potential window, low background current, and high stability of the surface. ${ }^{6}$ These properties cause the BDD surface not only to be biocompatible, but also difficult to be chemically changed or modified. $3,6,7$ Generally, physical change methods were used to modify BDD electrodes, including electrochemical deposition, ion implantation, and atomic sputtering. ${ }^{8-10}$ On the other hand, a photochemical reaction can provide a chemically nitrogenmodified BDD, resulting in a better stability of AuNPs attached at the BDD surface. ${ }^{3,6,11}$ As the biosensing agent, Rhodotorula mucilaginosa UICC Y-181, a species of yeast isolated from Jakarta Bay, Jakarta, Indonesia, was employed. ${ }^{3} R$. mucilaginosa UICC Y-181 was expected to be resistant for applications in extreme conditions, since Jakarta Bay is known to have high levels of pollution. This species can be found in air, soil, lakes, ocean water, as well as dairy products, colonized with plants, humans and other mammals. ${ }^{12}$ They are reported to be potential for applications in the degradation of nitrobenzene, ${ }^{12,13}$ the decolorization of azo dyes, ${ }^{14}$ and as a copper biosensor. ${ }^{15}$ In a previous report, a free cell of $R$. mucilaginosa UICC Y-181 in solution was utilized. ${ }^{6}$ However, this system has a limitation, since the microorganisms cannot be recovered for the next measurements. The immobilization of yeast was expected to increase the stability and the resistance against chemicals as 
well as to provide better kinetics at the electrode surface.

In this work, instead of free cells, the immobilization of $R$. mucilaginosa in an alginate matrix was utilized as a biosensing agent. Alginate, natural polysaccharide abundant in the cell walls of brown algae, is a linear copolymer composed of pattern blocks of homopolymeric regions of $\beta$ - $(1 \rightarrow 4)$-linked D-mannuronic acid $(\mathrm{M})$ and $\alpha$ - $(1 \rightarrow 4)$-linked L-guluronic acid (G). ${ }^{16}$ With divalent cations (e.g. $\left.\mathrm{Ca}^{2+}\right)$, alginate turns to gel formation through the crosslink carboxylate groups in the G-block of alginate, which leads to the formation of alginate macromolecular chain crosslinking. ${ }^{16-18}$ In addition to this unique gel formation, the flexible structure and highly adsorbent of the gel establishes it as a suitable matrix to immobilize yeast, enzyme, and living cells. ${ }^{16}$ Therefore, it was expected that no extreme change occurrs on $R$. mucilaginosa $\mathrm{Y}-181$ when it is being immobilized as well as during storage after immobilization. ${ }^{16}$ The result demonstrated that although the BOD sensor with immobilized $R$. mucilaginosa shows less sensitivity and less satisfactory LOD, however a better reproducibility of the current responses as well as better resistance from the influence of copper presence were observed.

\section{Experimental}

\section{Reagents and chemicals}

Glucose, peptone, sodium alginate, and other chemicals were of analytical grade, and supplied by Sigma-Aldrich. Yeast extract of $R$. mucilaginosa UICC Y-181, isolated from Jakarta Bay, Jakarta, Indonesia, was obtained from the University of Indonesia Culture Collection (UICC), Laboratory of Microbiology, Department of Biology, Faculty of Mathematics and Science, University of Indonesia. The yeast extracts were supplied in the form of culture in solutions of yeast glucose peptone broth containing $0.5 \%$ yeast extract, $0.5 \%$ peptone, and $4 \%$ glucose.

\section{Preparation of gold-modified BDD electrodes $(A u-B D D)$}

BDD films were deposited on $\mathrm{Si}$ (100) wafers in a microwave plasma-assisted chemical vapor deposition (MPCVD) system (Cornes Technologies). Methane and trimethyl boron (B/C ratio of 1:1000) were used as carbon and boron sources, respectively. Details of the preparation are described elsewhere with some modifications. ${ }^{6}$ SEM observed $3-5 \mu \mathrm{m}$ size of polycrystalline diamonds, while Raman spectra (Renishaw system 2000) showed a typical sharp and intense peak at $\sim 1333 \mathrm{~cm}^{-1}$ attributable to $\mathrm{sp}^{3}$ carbon as well as a couple of peaks at $\sim 500 \mathrm{~cm}^{-1}$ and $\sim 1200 \mathrm{~cm}^{-1}$ indicated the presence of disordered diamond due to being boron-doped. ${ }^{6,19}$ The absence of the $\mathrm{sp}^{2}$ carbon peak at $\sim 1600 \mathrm{~cm}^{-1}$ indicated that the film was of a fine quality. The SEM image and Raman spectra were provided in Supporting Information 1. Meanwhile, colloidal AuNPs were prepared as per Frens's procedure. ${ }^{20}$ Volumes of $0.5 \mathrm{~mL} 0.01 \mathrm{M}$ $\mathrm{HAuCl}_{4}$ and $18.5 \mathrm{~mL}$ water were stirred for $5 \mathrm{~min}$. Then, $0.5 \mathrm{~mL} 0.1 \mathrm{M}$ sodium citrate was added and stirred for $5 \mathrm{~min}$ before the addition of freshly prepared of $0.5 \mathrm{~mL} 0.1 \mathrm{M} \mathrm{NaBH}_{4}$. TEM was used to characterize the AuNPs. The BDD was modified by immersing the BDD in allylamine under UV irradiation $(\lambda=254 \mathrm{~nm})$ for $\sim 6 \mathrm{~h}$. After cleaning and drying, the BDD were immersed in colloidal AuNPs for $20 \mathrm{~min}$. X-ray photoelectron spectroscopy (XPS) was used for characterization.

\section{Preparation and Immobilization of the yeast}

The culture of $R$. mucilaginosa UICC Y-181 was incubated in a shaking incubator $(120 \mathrm{rpm})$ at $30^{\circ} \mathrm{C}$ for $24 \mathrm{~h}$, followed by
10 min of centrifugation. The biomass was then washed with distilled water and stored in a phosphate buffer solution (PBS) of $\mathrm{pH}$ 7. The growth curve was determined by incubating the yeast in several conical flasks with different incubation times, and monitored by observing its turbidity using a UV spectrophotometer at $600 \mathrm{~nm}$. An optimum growth of $24 \mathrm{~h}$ was observed. The number of yeast cells, which was determined using the Counting Chamber Method, concluded that $1 \mathrm{~mL}$ of a yeast suspension contained $2.56 \times 10^{8}$ yeast cells. In order to immobilize the yeast, a $10 \mathrm{~mL}$ yeast suspension was added into a solution of $40 \mathrm{~mL} 2.5 \%$ sodium alginate. With gentle stirring, $5 \mathrm{~mL} 2 \% \mathrm{CaCl}_{2}$ was added dropwise. The gel was then placed in the mold and kept at $4{ }^{\circ} \mathrm{C}$ for $2 \mathrm{~h}$. After that, a film of the gel was placed in a solution of $2 \% \mathrm{CaCl}_{2}$ for $10 \mathrm{~min}$, and then moved into a solution of $4 \% \mathrm{CaCl}_{2}$. After the gel solidified, the immobilized yeast was stored in an $8 \%$ sucrose solution at $4^{\circ} \mathrm{C}$.

\section{Electrochemical measurements of BOD sensors}

An electrochemical cell (5 mL volume) with a cover was used for the BOD sensor. An Au-BDD working electrode was positioned at the bottom of the cell. The contact area of the working electrode was estimated to be $0.26 \mathrm{~cm}^{2}$. A platinum wire and an $\mathrm{Ag} / \mathrm{AgCl}$ (saturated $\mathrm{KCl}$ ) system were used as counter and reference electrodes, respectively. An examination as an oxygen sensor was conducted by preparing $5 \mathrm{~mL}$ of $0.1 \mathrm{M}$ PBS pH 6.8 in the electrochemical cell. The solution was then purged with nitrogen for $5 \mathrm{~min}$, followed by oxygen aeration before cyclic voltammetry was conducted. The dissolved oxygen (DO) was confirmed using a DO meter. For BOD sensors, the film of immobilized yeast was placed on the working electrode at the bottom of the electrochemical cell. Then, the cell was filled with $4.5 \mathrm{~mL}$ of $0.1 \mathrm{M}$ PBS $\mathrm{pH}$ 6.8. To make a total glucose concentration of $0.5 \mathrm{mM}, 0.5 \mathrm{~mL}$ of $5 \mathrm{mM}$ standard glucose solution was added, followed by oxygen aeration for $5 \mathrm{~min}$. Then, the amperometric current was immediately measured and labeled as $I_{0}$. The waiting time for completing the assimilation process was optimized from 5 to 25 min. After an $x$-min waiting time, the current was measured and labeled as $I_{\mathrm{x}}$. A linear calibration curve for BOD was constructed from a various glucose concentrations. A comparison was made using free yeast cells, by adding $1 \mathrm{~mL}$ of a yeast suspension and $3.5 \mathrm{~mL}$ of PBS $\mathrm{pH} 6.8$ into the electrochemical cell before the addition of a glucose solution. The interference influence was studied in the presence of various concentrations of copper ions. The application on a real sample analysis was performed using water samples from three different areas of a lake in the University of Indonesia, Jakarta, Indonesia. Sampling analysis was performed within $2 \mathrm{~h}$ of collection. Before analysis, the samples were filtered using filter paper. A total standard of $0.5 \mathrm{mM}$ glucose was added into the sample solution. The results were verified using a standard method for the BOD measurement. ${ }^{1}$ Briefly, a $10 \mathrm{~mL}$ sample in a flask was added with $1 \mathrm{~mL}$ of $0.25 \mathrm{M}$ PBS pH $6.8,1 \mathrm{~mL}$ of $22.5 \mathrm{ppm}$ $\mathrm{MgSO}_{4} \cdot 7 \mathrm{H}_{2} \mathrm{O}, 1 \mathrm{~mL}$ of $27.5 \mathrm{ppm} \mathrm{CaCl}_{2}$, and $1 \mathrm{~mL}$ of $0.25 \mathrm{ppm}$ $\mathrm{FeCl}_{3}$ solutions. The solution was then saturated with oxygen by shaking the flask for $1 \mathrm{~h}$. The DO was immediately determined after the solution was diluted with water to $25 \mathrm{~mL}$ $\left(D_{1}\right)$, and after incubation at $20^{\circ} \mathrm{C}$ for 5 days $\left(D_{5}\right)$. The $\mathrm{BOD}_{5}$ was calculated as follows:

$$
\mathrm{BOD}_{5}\left(\mathrm{mg} \mathrm{L}^{-1}\right)=\left(D_{1}-D_{5}\right) / P \text {, where } P \text { is diluting factor }
$$



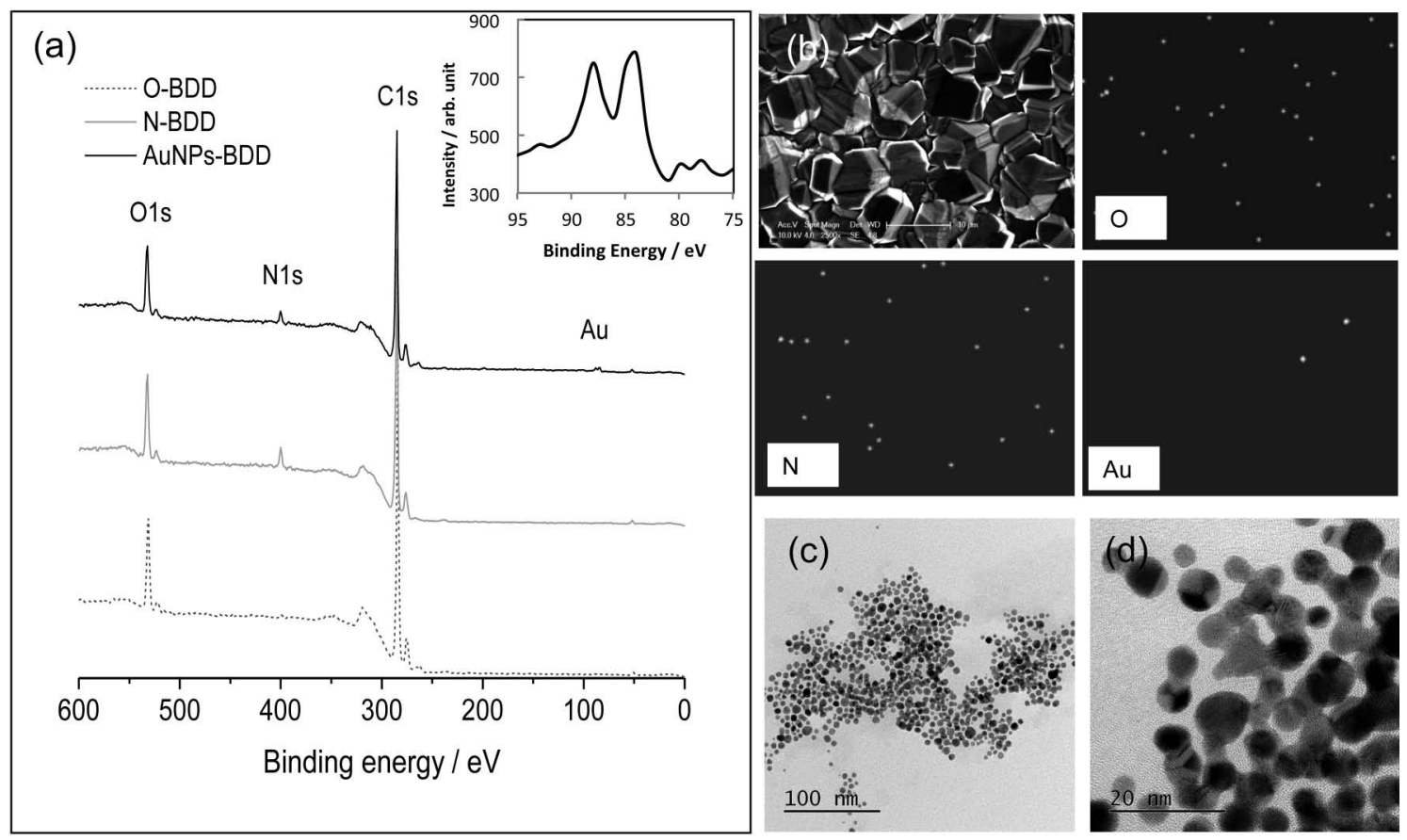

Fig. 1 (a) The XPS spectra of O-BDD, N-BDD, and AuNP-BDD with magnification of the Au $4 \mathrm{f}$ peak at the spectrum of AuNP-BDD shown in the Inset, (b) The SEM image of AuNP-BDD with EDX mapping of $\mathrm{O}, \mathrm{N}$, and $\mathrm{Au}$, and (c) The TEM images of colloidal AuNPs with (d) its magnifications.

\section{Results and Discussion}

\section{Preparation of gold-modified BDD electrodes ( $A u-B D D)$}

In order to attach the Au NPs to the surface of BDD, the surface was modified to nitrogen-terminated BDD (N-BDD). It was reported that N-BDD has a better affinity for gold particles than hydrogen- or oxygen-terminated BDDs (O-BDDs). ${ }^{3,11}$ A modification of the BDD surface with an amine functional group was performed using a photochemical reaction with allylamine under UV light $(\lambda=254 \mathrm{~nm})$ irradiation for $6 \mathrm{~h}$. This reaction is believed to involve energy from the UV light to break the double bonds of allylamine and to create new chemical bonds to the BDD surface.

Prior to the photochemical reaction, the surface of BDD was oxidized to be O-BDD so as to increase its hydrophilic property. Figure 1(a) shows the change of the XPS spectra of the BDD surface during the process. Typically, the spectra of the BDD surface show a peak attributable to bulk diamond (C 1s) at a binding energy of $-284.5 \mathrm{eV}$ as well as a couple peaks corresponding to $\mathrm{C}-\mathrm{OH}$ and $\mathrm{C}=\mathrm{O}$ at 534 and $550 \mathrm{eV}$, respectively. The calculated $\mathrm{O} / \mathrm{C}$ ratio of 0.3 was observed, which increased from an $\mathrm{O} / \mathrm{C}$ ratio of 0.02 of as-deposited BDD (Fig. S1, Supporting Information). This $\mathrm{O} / \mathrm{C}$ ratio is similar to the $\mathrm{O} / \mathrm{C}$ ratio of the BDD used in the previous work. It seemed to be that an oxidation process has occurred at that BDD.

After the photochemical reaction with allylamine, a new peak at $399 \mathrm{eV}$ corresponding to $\mathrm{N} 1 \mathrm{~s}$ was observed, indicating that $\mathrm{N}-\mathrm{BDD}$ could be formed. The spectrum shows an N/C ratio of 0.010 , which is similar to that of the N-BDD produced from photochemical reaction at the BDD from previous work. 3,11 This spectrum also shows that $\mathrm{O} / \mathrm{C}$ ratio decreased to 0.1 , indicating that the reaction with allylamine occurred at the oxygen site of the BDD surface, rather than at the carbon site. Furthermore, after immersing in the colloidal AuNPs, a couple of new peaks at binding energies of 83.7 and $87.2 \mathrm{eV}$ correspond to $\mathrm{Au} 4 \mathrm{f} 7 / 2$ and $\mathrm{Au} 4 \mathrm{f} 5 / 2$, respectively, was observed (Inset of Fig. 1(a)). An Au/C ratio of 0.29 was calculated. The immersion step also caused a decrease of the N/C ratio from 0.010 to 0.003, which confirmed that AuNPs were mainly attached at the nitrogen site at the BDD surface. ${ }^{3,11}$ The decrease of the N/C ratio suggested that it seems to be chemical bonds, and not only adsorption, formed between amino sites to AuNPs, which caused the peak of the nitrogen site at $399 \mathrm{eV}$ to be shifted or deconvoluted,

Furthermore, the EDX mapping shows the presence of AuNPs at the BDD surface although it is difficult to be visually noticed by an SEM image (Fig. 1(b)), since the AuNPs size was very small, i.e. $5-7 \mathrm{~nm}$ as shown by the TEM images in Figs. 1(c) and 1(d), a higher resolution of SEM is required to notice the attachment of the AuNPs at the BDD surface.

Examination of Oxygen Sensors and Immobilization of $R$. mucilaginosa

Examination of the electrode for oxygen sensors was conducted using cyclic voltammetry technique. Figure 2(a) shows, cyclic voltammograms (CVs) of $0.1 \mathrm{M}$ PBS pH 6.8 with a various concentrations of dissolved oxygen. In agreement to the previous report, ${ }^{3}$ two reduction peaks were observed at the potentials of -0.3 and $-0.6 \mathrm{~V}$ ( vs. $\mathrm{Ag} / \mathrm{AgCl})$. The peak current achieved the maximum at $\mathrm{pH} 6.8$ (data not shown). Therefore, $\mathrm{pH} 6.8$ was fixed for the next experiments. A linear calibration curve $\left(R^{2}=0.99\right)$, extracted from the peak currents at $-0.6 \mathrm{~V}$, was achieved from the concentration range of $2.7-10.3 \mathrm{ppm}$ oxygen (Fig. 2(b)). The result confirmed that the electrode was applicable as the oxygen sensors.

Since the BOD sensors are basically performed based on oxygen measurements, an aerobe type of microorganisms was selected for this work. $R$. mucilaginosa Y-181 is an aerobic microorganism with a high respiration level in nature. Therefore, 

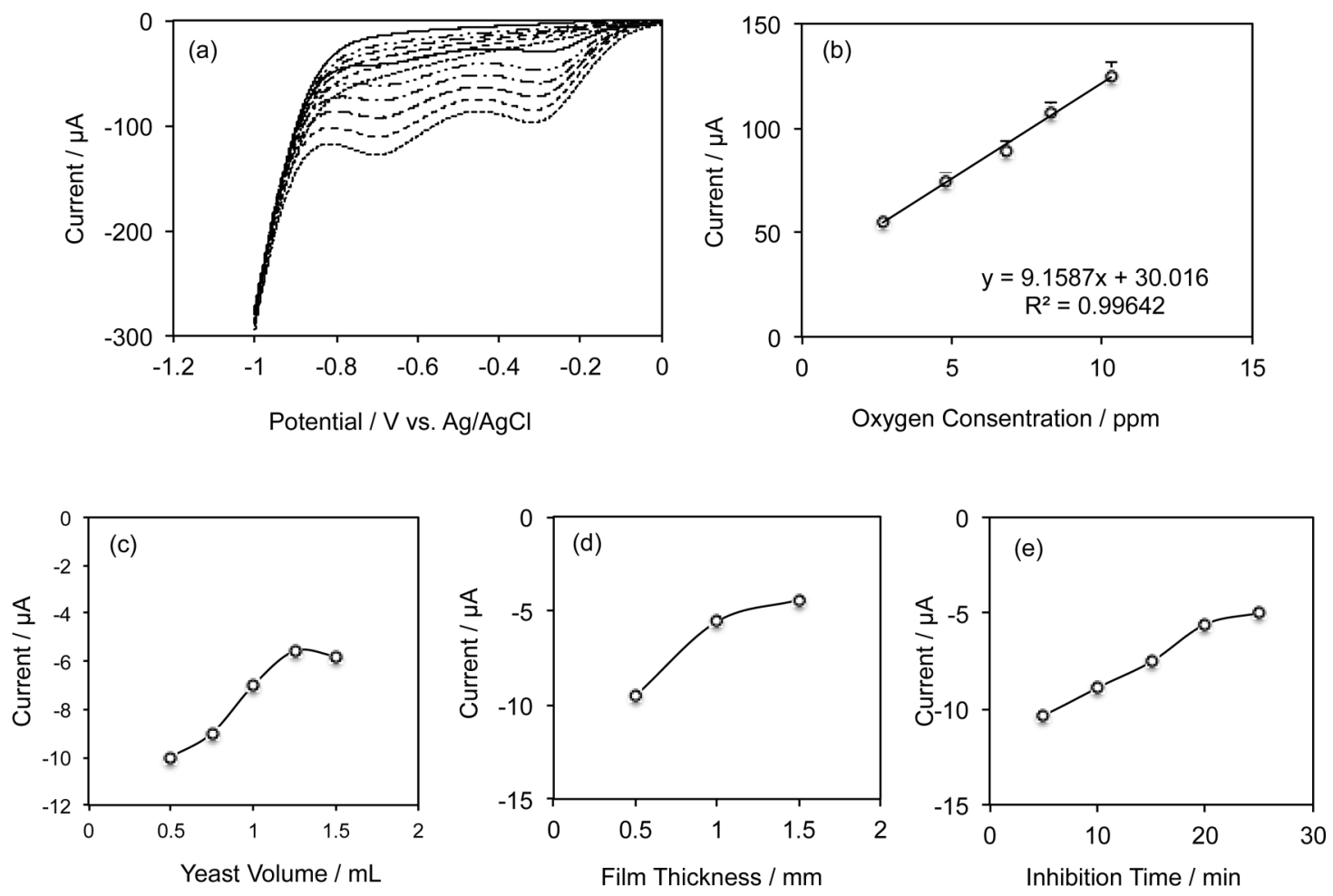

Fig. 2 (a) Cyclic voltammograms of various concentrations of dissolved oxygen in a $0.1 \mathrm{M}$ phosphate buffer solution, pH 6.8, at AuNP-BDD and (b) its linear calibration curve. The plots of peak currents, extracted from cyclic voltammograms at $-0.6 \mathrm{~V}$ in the presence of $0.5 \mathrm{mM}$ glucose, show the dependence of the peak currents on (c) the volume of yeast suspension, (d) the thickness of immobilized yeast film, and (e) the incubation time. A scan rate of $100 \mathrm{mV} / \mathrm{s}$ was applied.

it was expected to perform fast kinetics of the sensors. Prior to the immobilization of $R$. mucilaginosa, the optimum required number of the free cells in the system was investigated. As a model of carbon compounds, which will be decomposed by yeast, $0.5 \mathrm{mM}$ glucose or equivalent to $50 \mathrm{mg} / \mathrm{L} \mathrm{BOD,}{ }^{21}$ was presented in the system. Theoretically, the yeast will oxidize glucose by consuming oxygen, resulting in a decrease of the oxygen concentration in the solution. ${ }^{2-5}$ Figure 2(c) shows the plot dependence of the reduction peak currents of oxygen on the volume of free $R$. mucilaginosa cells added in the solution. A decrease of the currents was observed in the presence of 0.5 to $1.5 \mathrm{~mL}$ cell suspension. However, after a $1 \mathrm{~mL}$ addition of the cells, the decrease of the current was not significantly changed. This data also confirmed the previous result. ${ }^{3}$ Therefore, a 1 $\mathrm{mL}$-volume of the free cell suspension or a number of $2.56 \times$ $10^{8}$ cells was fixed to use for the next experiments.

Immobilization of $R$. mucilaginosa $\mathrm{Y}-181$ was performed in an alginate matrix, a type of polysaccharide, composed of D-mannuronic acid and L-guluronic acid. In addition to its good permeability, non-toxic property, and transparency, alginate also has the ability to form gel by reactions with positive ions. The strength of the gel depends on the alginate composition and the cross-linker ions, which is added during the polymerization process. ${ }^{16}$ However, since the electrochemical technique was affected by material diffusion to the electrode surface, the thickness of the film becomes an important factor. The influence of the film thickness was investigated using a total number of $2.56 \times 10^{8} R$. mucilaginosa cells, which are immobilized in various film thicknesses. Figure 2(d) shows the dependence plots of the amperometric current responses on the film thickness. The film shows that a significant decrease of the current was observed and reached its optimum at a film thickness of $1 \mathrm{~mm}$. Furthermore, by utilizing the same numbers of $R$. mucilaginosa cells immobilized in a film thickness of $1 \mathrm{~mm}$, the optimum inhibition time was investigated, which shows the optimum inhibition time at 25 min (Fig. 2(e)). This inhibition time was similar to the previous result with the free-cells system, ${ }^{3}$ indicating that there is no significant difference of the kinetic of the microorganisms in the free or immobilized condition.

\section{Examination as BOD sensors}

An examination for BOD sensors was performed using various concentrations of glucose solutions in PBS pH 6.8. Figures 3(a) - 3(e) show typical amperograms generated immediately and at 25 min after oxygen aeration for glucose concentration range of $0.1-0.5 \mathrm{mM}$, respectively, at a potential of $-0.6 \mathrm{~V}$. A film thickness of $1 \mathrm{~mm}$ containing of $2.56 \times 10^{8} R$. mucilaginosa cells was used. These figures show that the consumed oxygen increases with the increase of the glucose concentration. The dependence of the consumed oxygen on the glucose concentrations is displayed in Fig. 3(f). A linear calibration curve $\left(R^{2}=0.99\right)$ was observed with an estimated LOD of $0.019 \mathrm{mg} / \mathrm{L}$ BOD, or equivalent to $1.9 \mathrm{mg} / \mathrm{L}$ BOD. A good reproducibility $(n=3)$ was shown with the average error bars smaller than $3.35 \%$.

A comparison was performed between the BOD sensors with free cells against the immobilized cells of $R$. mucilaginosa for various film thicknesses. A summary is displayed in Table 1. The Table shows that the systems with immobilized films have less sensitivity than the system with free cells, which is reasonable, since the films can block the diffusion of oxygen to 

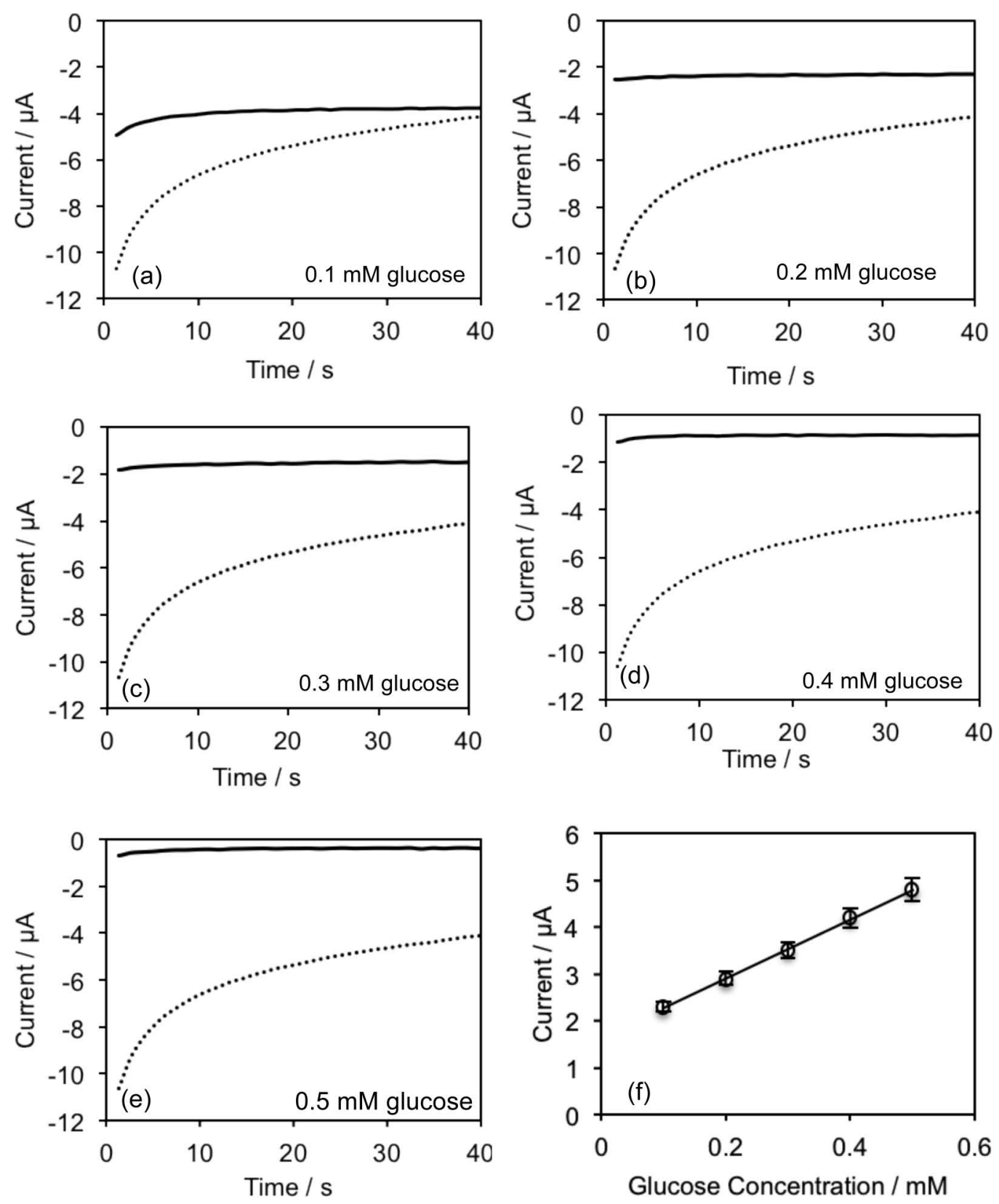

Fig. 3 (a-e) Typical amperograms of a various concentrations of glucose from $0.1 \mathrm{mM}$ to $0.5 \mathrm{mM}$ in a phosphate buffer solution $\mathrm{pH} 6.8$ conducted at $0 \mathrm{~min}$ and 25 th min after oxygen aeration a potential of $-0.6 \mathrm{~V}(v s . \mathrm{Ag} / \mathrm{AgCl})$. An immobilized film containing of $2.56 \times 10^{8} R$. mucilaginosa cells with a film thickness of $1 \mathrm{~mm}$ was used as the biosensing agent. The dependence of the peak currents on the glucose concentrations is shown in (f).

the electrode surface. Moreover, a less-satisfactory LOD in comparison to the free-cells system was also observed.

In fact, the reproducibility of these measurements depends on two factors, including the stability of the electrode, i.e. Au-BDD electrode, and the stability of the sensing agent; in this case it was $R$. mucilaginosa immobilized in an alginate matrix. A previous result using free cells of $R$. mucilaginosa as the biosensing agent showed excellent stability of the electrode, which was proposed to be due to the chemical bonds formation between gold nanoparticles and the BDD surface. ${ }^{3}$ These chemical bonds have successfully provided a better stability of the gold nanoparticles attachment at the BDD surface, conditioning the yeast cells free from gold particles influence. ${ }^{3}$ Further, since the system with free cells needs new yeast cells for every measurement, while the system with immobilized one is expected to reuse the immobilized cells, a very good stability of the immobilized film is required. In this case, the evidence of good reproducibility of the current responses shown by the system with an immobilizes cells indicated that $R$. mucilaginosa cells can be immobilized in stable films using an alginate matrix. The stability of the film during the storage was also investigated, which showed that the film can be used for three consecutive days without any fouling or decreasing of its sensitivity.

It is reported that the oxygen consumed by $R$. mucilaginosa was influenced by the presence of copper ions in the solution. ${ }^{3,12}$ The higher the copper concentration, the higher the signal current of oxygen, since the presence of copper ions causes 


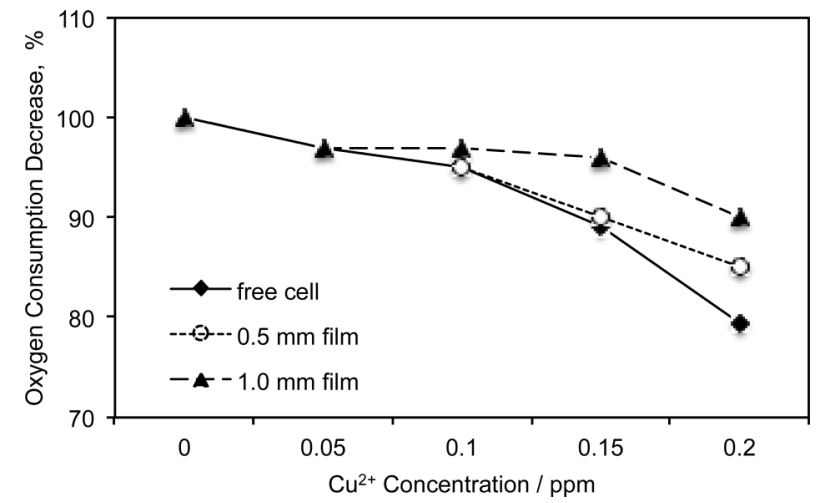

Fig. 4 Influence of the presence of copper ions on the decrease of the oxygen consumption in BOD sensors applied with free and immobilized cells of $R$. mucilaginosa. The other condition was similar to Fig. 3.

Table 1 Performance of the developed BOD sensors using free and immobilized $R$. Mucilaginosa in several different film thickness

\begin{tabular}{lccc}
\hline $\begin{array}{c}R . \text { mucilaginosa } \\
\text { Cell }\end{array}$ & $\begin{array}{c}\text { Slope/ } \\
\mu \mathrm{A} \mathrm{mgL}^{-1} \text { BOD }\end{array}$ & $\begin{array}{c}\mathrm{LOD} / \\
\mathrm{mg} \mathrm{L}^{-1}\end{array}$ & $\begin{array}{c}\text { Minimum } \mathrm{Cu}^{2+} \\
\text { Interference/ppm }\end{array}$ \\
\hline $\begin{array}{c}\text { Free cells } \\
\text { Immobilized }(0.5 \mathrm{~mm}\end{array}$ & 8.5 & 1.13 & 0.08 \\
$\begin{array}{c}\text { thickness) } \\
\text { Immobilized (1.0 mm } \\
\text { thickness) }\end{array}$ & 6.0 & 1.2 & 0.08 \\
$\begin{array}{c}\text { Immobilized (2.0 mm } \\
\text { thickness) }\end{array}$ & $\mathrm{NA}$ & $\mathrm{NA}$ & - \\
\hline
\end{tabular}

Each film contained of $2.56 \times 10^{8}$ yeast cells immobilized in an alginate matrix.

some $R$. mucilaginosa cells to become inactive. Therefore, in this work, an interference study to the system with immobilized yeast was conducted using copper ions. Figure 4 displays the decrease of the oxygen consumption in the system, converted from the oxygen signal from the developed BOD sensors at $-0.6 \mathrm{~V}$ (vs. $\mathrm{Ag} / \mathrm{AgCl}$ ). The Figure shows that whereas the system with free cell and $0.5-\mathrm{mm}$ immobilized film can suppress the copper ions influence at the concentration less than $50 \mathrm{ppb}(0.08 \mu \mathrm{M})$, the system with higher thickness of yeast film can control the influence of higher copper concentration, i.e. $0.12 \mu \mathrm{M}$. Apparently the immobilization of the $R$. mucilaginosa in the alginate film induces more resistance against any copper influence toward the microorganisms. Further measurements of the system with the presence of 0.15 and $0.2 \mu \mathrm{M}$ copper ions increased the current responses up to $\sim 8$ and $\sim 15 \%$, respectively. It seems to be at a higher concentration than $0.12 \mu \mathrm{M}$, some $R$. mucilaginosa cells to become inactive, or even to perish.

An examination for a real sample was then performed using water samples taken from four different parts of a lake at the University of Indonesia in Jakarta on August 2014, at 10.00 a.m. The samples have an average of $\mathrm{pH} 7.5$, total dissolved solids of $519-528 \mathrm{mg} / \mathrm{L}$, and COD values of $47-54 \mathrm{mg} / \mathrm{L}$ without a significant amount of heavy metal ions being observed. A standard addition of $0.05 \mathrm{mM}$ glucose was added into the sample before dilution in $0.1 \mathrm{M}$ PBS. A measurement was conducted using the conventional method as well as using a
Table 2 Comparison of BOD values of water samples from a lake at the University of Indonesia in Jakarta measured by the Standard Method ${ }^{1}$ and using the developed methods

\begin{tabular}{ccc}
\hline $\begin{array}{c}\text { BOD values } \\
\text { measured using the } \\
\text { conventional method }\end{array}$ & $\begin{array}{c}\text { BOD values } \\
\text { measured using the } \\
\text { developed method } \\
\text { with free cells of } R \text {. } \\
\text { mucilaginosa }\end{array}$ & $\begin{array}{c}\text { BDD values } \\
\text { measured using the } \\
\text { developed methods } \\
\text { with 1 mm thickness } \\
\text { of immobilized } R \\
\text { mucilaginosa }\end{array}$ \\
\hline $17 \pm 1$ & $17 \pm 2$ & $16 \pm 1$ \\
$17 \pm 2$ & $19 \pm 1$ & $17 \pm 2$ \\
$20 \pm 2$ & $18 \pm 2$ & $17 \pm 2$ \\
$21 \pm 1$ & $20 \pm 2$ & $19 \pm 1$ \\
\hline
\end{tabular}

biosensor with free and immobilized $R$. mucilaginosa cells. The measurement data are shown in Table 2. Comparable results to that of the conventional method suggested that the method is suitable for BOD measurements.

\section{Conclusions}

Electrochemical yeast-based BOD sensors with free and immobilized cells of Rhodotorula mucilaginosa UICC Y-181 in an alginate matrix were successfully developed using gold nanoparticle modified BDD electrodes.

BOD values was obtained through oxygen reduction measurements by applying the optimum condition with $2.56 \times$ $10^{8} R$. mucilaginosa cells in a film thickness of $1 \mathrm{~mm}$, a waiting time of $25 \mathrm{~min}$, and an amperometric potential of $-0.6 \mathrm{~V}$. A linear calibration curve can be achieved in the concentration range of $0.1-0.5 \mathrm{mM}$ glucose or equivalent to $10-50 \mathrm{mg} / \mathrm{L}$ BOD. Better sensitivity as well as LOD were shown for measurements using free cells of $R$. mucilaginosa UICC Y-181.

However, better stability as well as resistance for copper interference was shown by the system using the immobilized cells. The sensor applied for BOD measurements of water samples from the lake at the University of Indonesia in Jakarta, which showed comparable results, suggested that the developed sensor can be applied for real applications.

\section{Acknowledgements}

This work is partialy funded by Hibah Riset Kolaborasi Internasional Universitas Indonesia Contract No. 1835/H2.R12/ HKP.05.00.Perjanjian/2014.

\section{Supporting Information}

Characterization of as deposited boron-doped diamond electrodes represented by (a) SEM image, (b) Raman spectra and (c) XPS spectra. This material is available free of charge on the Web at http://www.jsac.or.jp/analsci/.

\section{References}

1. "Standard Method for the Examination of Waters and Wastewater", 1986, 16th ed., American Public Health Association, Washington, D.C. 
2. I. Karube, T. Matsunaga, S. Mitsuda, and S. Suzuki, Biotechnol. Bioeng., 1977, 19, 1535.

3. T. A. Ivandini, E. Saepudin, H. Wardah, Harmesa, N. Dewangga, and Y. Einaga, Anal. Chem., 2012, 84, 9825.

4. H. Nakamura, Y. Mogi, H. Hattori, Y. Kita, D. Hattori, A. Yoshimura, and I. Karube, Anal. Chim. Acta, 2008, 620, 127.

5. X. C. Abrevaya, N. J. Sacco, M. C. Bonetto, A. HildingOhlsson, and E. Corton, Biosens. Bioelectron., 2015, 63, 580.

6. "Diamond Electrochemistry", ed. A. Fujishima, Y. Einaga, T. N. Rao, and D. A. Tryk, 2005, BKC-Elsevier, Tokyo.

7. L. Ouattara, I. Duo, T. Diaco, A. Ivandini, K. Honda, T. Rao, A. Fujishima, and C. Comninellis, New Diamond Front. Carbon Technol., 2003, 13, 97.

8. B. Rismetov, T. A. Ivandini, E. Saepudin, and Y. Einaga, Diamond Relat. Mater., 2014, 48, 88.

9. T. A. Ivandini, R. Sato, Y. Makide, A. Fujishima, and Y. Einaga, Chem. Lett., 2004, 33, 1330.

10. T. A Ivandini, Y. Naono, A. Nakajuima, and Y. Einaga, Chem. Lett., 2005, 34, 1086.
11. R.-h. Tian, T. N. Rao, Y. Einaga, and J.-F. Zhi, Chem Mater, 2006, 18, 939

12. Z. Chunli, Z. Jiti, W. Jing, W. Jing, H. Lu, and H. Zhao, J. Hazard. Mater., 2009, 168, 298.

13. Z. Chunli, Z. Jitii, W. Jing, W. Jing, and Q. Baocheng, J. Hazard. Mater., 2008, 160, 194.

14. T. A. Onat, H. T. Gumusdere, A. Guvenc, G. Donmez, and U. Mehmetoglu, Desalination, 2010, 225, 154.

15. M. Yuce, H. Nazir, and G. Donmez, Bioelectrochemistry, 2010, 79, 66

16. Y. Cheng, X. Luo, J. betz, G. F. Payne, W. E. Bentley, and G. W. Rubloff, Soft Mater., 2011, 7, 5677.

17. E. R. Morris, D. A. Rees, D. Thom, and D. Boyd, Carbohydr. Res., 1978, 66, 145.

18. D. Thom, G. T. Grant, E. R. Morris, and D. A. Rees, Carbohydr. Res., 1982, 100, 29.

19. Y. Honda, T. A. Ivandini, T. Watanabe, K. Murata, and Y. Einaga, Diamond Relat. Mater., 2013, 40, 7.

20. G. Frens, Nat. Phys. Sci., 1973, 241, 20.

21. K. Riedel, K. P. Lange, H. J. Stein, M. Kuh, P. Ott, and F. Scheller, Water. Res., 1990, 24, 883. 